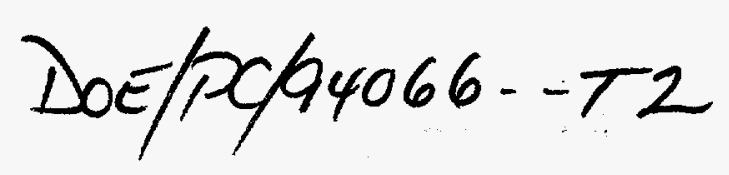

\title{
Isobutanol-Methanol Mixtures from Synthesis Gas
}

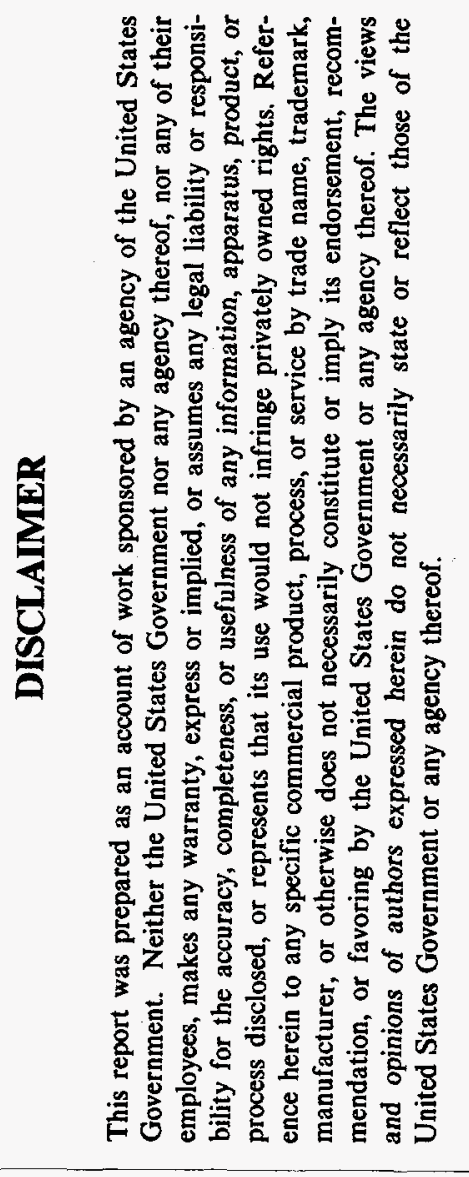

\author{
Quarterly Technical Progress Report
}

\author{
Period Covered: 1 January to 31 March 1995
}

Contractor

University of California-Berkeley
Berkeley, California 94720

Enrique Iglesia - Program Manager

24 April 1995

Prepared for the United States Department of Energy *

Under Contract Number DE-AC22-94PC94066

Contract Period 1 October 1994 - 30 September 1997

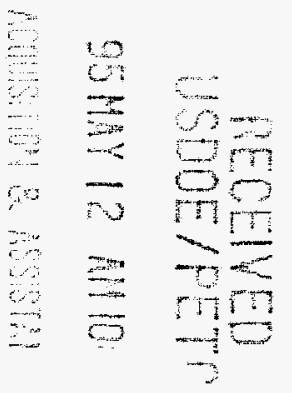

\footnotetext{
* This report is an account of work sponsored by the United States Government. Neither the United States not the United States Department of Energy, nor any of their employees, nor any of their contractors, subcontractors, or their employees, make any warranties, express or implied, or assumes any legal responsibility or liability for the accuracy, completeness, or usefulness of any information, apparatus, product, or process disclosed or represents that its use would not infringe privately owned rights.
} 


\section{DISCLAIMER}

This report was prepared as an account of work sponsored by an agency of the United States Government. Neither the United States Government nor any agency thereof, nor any of their employees, make any warranty, express or implied, or assumes any legal liability or responsibility for the accuracy, completeness, or usefulness of any information, apparatus, product, or process disclosed, or represents that its use would not infringe privately owned rights. Reference herein to any specific commercial product, process, or service by trade name, trademark, manufacturer, or otherwise does not necessarily constitute or imply its endorsement, recommendation, or favoring by the United States Government or any agency thereof. The views and opinions of authors expressed herein do not necessarily state or reflect those of the United States Government or any agency thereof. 


\section{DISCLAIMER}

Portions of this document may be illegible in electronic image products. Images are produced from the best available original document. 


\section{TABLE OF CONTENTS}

\section{CONTRACT OBJECTIVES AND TASKS}

\section{SUMMARY OF ACTIVITIES}

\section{STATUS, ACCOMPLISHMENTS, RESULTS}

Task 1: Project Work Plan

Task 2 : Catalyst Synthesis

Preparation of Alcohol Synthesis and Coupling Catalysts

1. Methanol Synthesis Catalysts

2. Isobutanol Synthesis catalysts

3. Aldol Coupling/Alcohol coupling catalysts

Catalyst Characterization

Task 3: Catalyst Evaluation in Laboratory Scale Reactors

Construction and Start-up of Catalytic Microreactor Unit Strategies for the Design of Isobutanol Synthesis Catalysts Mechanistic Studies of Alcohol Coupling Pathways

Task 4: Identification of Reaction Intermediates

Task 5: Bench-Scale Catalyst Evaluation at Air Products and Chemicals 


\section{CONTRACT OBJECTIVES AND TASKS}

The contract objectives are:

1. To design a catalytic material for the synthesis of isobutanol with a productivity of $200 \mathrm{~g}$ isoalcohols/g-cat-h and a molar isobutanol/methanol ratio near unity

2. To develop structure-function rules for the design of catalysts for the selective conversion of synthesis gas to isoalcohols

The research program has been grouped into four specific tasks and a set of project management and reporting activities. Subsequent to the acceptance of the management plan, the following are the revised abbreviated titles for the tasks.

- Project Work Plan (Task 1)

- Catalyst Synthesis (Task 2)

- Catalyst Evaluation in Laboratory Scale Reactors (Task 3).

- Identification of Reaction Intermediates (Task 4)

- Bench-Scale Catalyst Evaluation at Air Products and Chemicals (Task 5).

\section{SUMMARY OF ACTIVITIES}

Several catalyst samples have been prepared by controlled co-precipitation from aqueous mixtures of metal nitrates. The composition of these materials is based on reports of best available catalysts for methanol synthesis, for isobutanol synthesis, and for methanol coupling reactions. The mechanical construction and pressure testing of the microreactor system has been completed. The in-situ infrared spectrophotometer equipped with a nitrogen purge is fully operational. The temperature-programmed surface reaction (TPSR) unit has been designed; construction will begin during the third quarter FY'95. Air Products and Chemicals has provided us with a sample of a BASF isobutanol synthesis catalyst and with catalytic data obtained on this catalyst in a LaPorte test run. This catalyst will serve as a benchmark for the certification of our new microreactor system.

The Work Management Plan, Milestone Schedule Status, and the Cost Plan were revised as requested by the DOE Contracting Officer. These documents were accepted for distribution. 


\section{STATUS, ACCOMPLISHMENTS, RESULTS \\ (by reporting elements/tasks)}

\section{Task 1: Project Work Plan}

Monthly status reports for January, February and March were prepared and sent to the Department of Energy. The Management Plan, Cost Plan, Milestone Schedule, and Notice of Energy R\&D were submitted to the Department of Energy on October 30, 1994. These documents were received with comments from the DOE Contracting Officer on December 21, 1994. Revised versions of these documents were resubmitted in January to the Department of Energy. These documents were approved for distribution by the DOE Contracting Officer on March 13, 1995.

\section{Task 2 : Catalyst Synthesis}

\section{Preparation of Alcohol Synthesis and Coupling Catalysts}

After completion of the Controlled pH Precipitation Unit (CPPU) during 1Q'95, initial synthesis activities have focused on the synthesis of mixed-metal oxides and $\mathrm{CuO}$ precursors under constant $\mathrm{pH}$ and temperature conditions. The CPPU apparatus was certified by precipitation of zirconium hydroxide precursors from zirconyl chloride at a constant $\mathrm{pH}$ values between 9 and 11 .

Several catalytic solids have been prepared using the controlled precipitation apparatus. These materials will be used in the initial mechanistic studies of isobutanol synthesis pathways (Task 3 ). These materials have been precipitated as metal hydroxides from nitrate precursors. We have focused the initial synthesis studies on three type of materials: methanol synthesis catalysts, isobutanol synthesis catalysts, and alcohol coupling catalysts based on high surface area metal oxide catalysts.

\section{Methanol Synthesis Catalysts:}

Copper-based methanol synthesis catalysts have been prepared to be used as the hydrogenation-dehydrogenation component in physical mixtures of basic oxides/hydrogenation catalysts. The synthesis procedures follow those reported in the open literature [Catal. Lett. 2, 49-56 (1989)]. The following catalysts have been prepared:

- $\mathrm{Cu} / \mathrm{Zn}$ (65:35 atomic ratio) - prepared by co-precipitation from a solution of $\mathrm{Cu}$ and $\mathrm{Zn}$ nitrates by the controlled addition of ammonium hydroxide to maintain a constant $\mathrm{pH}$ of 9.0 .

- $\mathrm{Cu} / \mathrm{Zn}$ (65:35 atomic ratio) - prepared by co-precipitation from a solution of $\mathrm{Cu}$ and $\mathrm{Zn}$ nitrates by the controlled addition of a sodium carbonate-sodium 
hydroxide solution to maintain a constant $\mathrm{pH}$ of 9.0 . The resulting solid was subsequently washed in hot water to remove soluble $\mathrm{Na}$ cations.

- $\mathrm{Cu} / \mathrm{Zn}$ catalyst (30:70 atomic ratio) - prepared by coprecipitation from a solution of $\mathrm{Cu}$ and $\mathrm{Zn}$ nitrates by the controlled addition of potassium hydroxide-potassium carbonate mixture to maintain a constant $\mathrm{pH}$ of 9 . It was subsequently washed in hot water to remove any residual potassium cations.

\section{Isobutanol Synthesis catalysts}

These isobutanol synthesis catalysts were chosen as the three leading candidates reported in the literature. They have been prepared under controlled $\mathrm{pH}$ conditions. The following literature isobutanol synthesis catalysts have been prepared during this performance period:

\section{Zr:Zn:Mn (1:1:1 atomic ratio) promoted with $\mathrm{Cu}$ -}

This catalyst represents a modification of the materials reported by Keim, et al. [Catal. Lett. 3, 9-63 (1989)]. The Keim isobutanol synthesis catalysts are active and selective at conditions much more severe than those targeted by our studies. As a result, we have replaced the Pd hydrogenation component used by Keim and co-workers in their most selective catalysts with $\mathrm{Cu}$ in order to introduce significant methanol synthesis activity at lower temperatures.

The $\mathrm{Zr}-\mathrm{Zn}-\mathrm{Mn}$ mixed oxide was prepared by coprecipitation of mixed nitrate solution at a constant $\mathrm{pH}$ of 10 using sodium hydroxide. This $\mathrm{pH}$ was chosen in order to ensure the precipitation of Mn hydroxide, which occurs at $\mathrm{pH}$ values above 8 . This material will be tested for alcohol coupling reactions before impregnation with $\mathrm{Cu}$. A portion of this sample will be impregnated with $\mathrm{Cu}$; this sample will be used for both alcohol coupling and isobutanol synthesis studies.

\section{Cu-Zn-Mn (4:3:1 atomic ratio) -}

This sample is based on isobutanol synthesis catalysts reported by Stiles, et al. [Ind. Eng. Chem. Res. 30, 811-821 (1991)]. Our initial studies will exclude the Co and Cs components, which will then be incorporated in subsequent formulations in order to test the independent effects of these additional components on isobutanol synthesis rates and selectivity. The sample was prepared by coprecipitation of mixed-metal nitrate solutions at a $\mathrm{pH}$ of 10.0, using a mixture of sodium carbonate and sodium hydroxide. It was then filtered and washed with hot water to remove soluble sodium species. 


\section{$\mathrm{Cu}: \mathrm{Zn}: \mathrm{Cr}(30: 45: 25$ atomic ratio $)-$}

This catalyst is based on the work of Klier's group [Inorg. Chem. 28, 3868-3874 (1989)]. Cs doping of this materials leads to isobutanol productivities of $50 \mathrm{~g} / \mathrm{kg}$ cat-hr. This sample was prepared by coprecipitation from a solution of metal nitrates at a $\mathrm{pH}$ of 9 using sodium hydroxide and sodium carbonate. The samples will then be impregnated with Cs formate to give the chemical composition of the best isobutanol synthesis catalyst from this group. Cs formate will be used because it appears to lead to higher alkali dispersion than other Cs salts.

\section{Mn-Containing Metal Oxides -}

Mn oxides appear to play a significant role in the formation of mixed oxides with high surface area and strong basicity. A survey of the catalysts that give high isobutanol yield shows that they frequently contain $\mathrm{Mn}$ as a critical component [A. Sofianos, Catal. Today 15, 149-175 (1992)]. A series of $\mathrm{Mn}$-containing catalysts were prepared in order to examine the role of $\mathrm{Mn}$ on the catalyst surface area and basicity, and on alcohol coupling rates. $\mathrm{Mn}$ is also likely to influence the $\mathrm{Cu}$ dispersion after impregnation with a $\mathrm{Cu}$ salt and reduction. These dispersion effects will be studied by preparing catalysts with varying $\mathrm{Cu}$ concentrations on a series of $\mathrm{Mn}$ containing oxides.

$\mathrm{Mn}-\mathrm{Zn}$ mixed oxide samples were prepared by precipitation at a constant $\mathrm{pH}$ of 10 using a mixture of potassium carbonate-potassium hydroxide mixture. Potassium was used because literature reports seem to suggest that residual $\mathrm{K}$ improves catalytic performance but residual $\mathrm{Na}$ does not [Stiles, et al. Ind. Eng. Chem. Res., 30 , 811-821 (1991)]. Catalysts with the following $\mathrm{Cu}: \mathrm{Zn}: \mathrm{Mn}$ ratios have been prepared: 4:3:1, 4:1:3, 1:1:1, $4: 3: 3,4: 3: 0$.

\section{Aldol Coupling/Alcohol coupling catalysts}

The aldehyde/alcohol coupling step is an important step in the synthesis of the isobutanol from synthesis gas. The coupling between two aldehydes containing $\beta$ hydrogens to form a branched aldehydes (aldol condensation) requires basic catalysts. The alcohol coupling reaction of interest in isobutanol synthesis would then require dehydrogenation of alcohols to the corresponding aldehyde followed by aldol condensation of the latter on basic metal oxides.

$\mathrm{MgO}$ is known to catalyze the condensation of alcohols to form higher alcohols, even without the presence of a separate dehydrogenation function [Ueda et al., Catal. 
Lett. 1992, 12, 97-104 (1992)]. However, MgO sinters readily in the presence of water at envisioned isobutanol synthesis temperatures leading a rapid and marked decrease in surface area from initial values above $200 \mathrm{~m}^{2} / \mathrm{g}$ to less than $100 \mathrm{~m} / \mathrm{g}$. The presence of $\mathrm{Al}$ oxides appears to stabilize high surface area $\mathrm{MgO}$ under hydrothermal conditions. Segregation of a separate alumina phase in these metal oxides, however, would be detrimental because the resulting acid sites would catalyze dehydration of required alcohol intermediates to ethers. The atomic mixing between magnesium and aluminum oxides in materials prepared from hydrotalcite precursors should introduce the stabilizing effects of $\mathrm{Al}$ oxide species without the deleterious formation of a separate alumina phase.

Hydroxycarbonate precursors with hydrotalcite structures and general composition have general formulas of the type: $\left(\mathrm{A}^{+2}\right)_{6}\left(\mathrm{~B}^{+3}\right)_{2}(\mathrm{OH})_{16}\left(\mathrm{CO}_{3}\right)^{2-} 4 \mathrm{H}_{2} \mathrm{O}$, where, $\mathrm{A}$ can be $\mathrm{Mg}, \mathrm{Mn}, \mathrm{Co}, \mathrm{Zn}, \mathrm{Cr}$ and $\mathrm{B}$ can be $\mathrm{Al}, \mathrm{Fe}, \mathrm{Cr}$ etc. Metal oxides prepared by calcination of hydrotalcite precursors have been used as catalysts for base-catalyzed reactions. These hydrotalcites materials offer compositional flexibility and form high surface area mixed-metal oxides after calcination at 300-500 C. [(F. Cavani et al. Catal. Today 11, 173-301 (1991)]. Calcined Mg-Al hydrotalcites have been shown to be selective to the formation of propanone in 2-propanol dehydration, a base-catalyzed reaction [McKenzie et al. J. Catal. 138, 547 (1992)].

The usual composition of $\mathrm{Mg}: \mathrm{Al}$ hydrotalcites is 3:1. Hydrotalcite structures, however, can accommodate $\mathrm{Mg}$ :Al ratios from 2:1 to 10:1 under controlled synthesis conditions. [Schaper et al. Appl. Catal. 54, 79 (1989)]. Samples with the following $\mathrm{Mg}$ :Al ratios: 1:0, 1.5:1, 2.5:1, 5:1, 10:1 have been prepared from hydrotalcite precursors. The $\mathrm{Mg}: \mathrm{Al}(1.5: 1)$ sample consists of a mixture of $\mathrm{Mg}$ aluminate and hydrotalcite phases, while the other compositions form pure hydrotalcites. These materials have been calcined at a temperature of $500 \mathrm{C}$ for $12 \mathrm{~h}$ to form the mixed-metal oxides. Surface areas are being determined by $\mathrm{N}_{2}$ physisorption and the density of basic sites will be measured by $\mathrm{CO}_{2}$ chemisorption. The compositional range of these samples will allow the study of $\mathrm{Al}$ effects on the basicity and surface area stability of $\mathrm{Mg}$ oxides. These samples will be initially evaluated in alcohol coupling reactions before the introduction of an additional hydrogenation function in the form of physically admixed $\mathrm{Cu} / \mathrm{ZnO}$ co-catalysts.

\section{Catalyst Characterization}

These materials will be characterized by powder X-ray diffraction and BET surface area measurements and transmission electron microscopy. The phase purity of the samples would be ascertained by powder X-ray diffraction. $\mathrm{CO}_{2}$ chemisorption will be used to quantify basic sites while $\mathrm{N}_{2}$ physisorption will be used to determine the physical surface area of the samples described above. Transmission electron microscopy will be used to estimate the $\mathrm{Cu}$ crystallite distribution and the phase purity of the mixed oxides at a microscopic scale.

Scoping studies of the structure of $\mathrm{Cu}$ and $\mathrm{Zn}$ components in methanol and higher alcohol synthesis catalysts using X-ray absorption fine structure spectroscopy (XAFS) 
have been carried out at the Stanford Linear Accelerator in collaboration with Dr. George D. Meitzner, Chief Scientist, Edge Analytical. This technique provides local structure information around $\mathrm{Cu}$ and $\mathrm{Zn}$ atoms. XAFS experiments can be performed in-situ at pressures up to 5 bar and temperatures up to $500 \mathrm{C}$.

\section{Task 3: Catalyst Evaluation in Laboratory Scale Reactors}

\section{Construction and Start-up of Catalytic Microreactor Unit}

The mechanical construction of the Catalytic Microreactor Unit has been completed on schedule. CMRU presently contains a single-pass flow reactor module capable of handling $0.1-10 \mathrm{~g}$ of catalyst. The internal recirculating reactor module will be designed during $4 \mathrm{Q}^{\prime} \mathrm{FY} 95$. An updated schematic flow diagram and a list of components is included as Figure 1 in this quarterly technical report.

A Hewlett-Packard Gas Chromatograph/Mass Selective Detector has been calibrated to identify all chemical species present in a typical alcohol product mixture from the APCI LaPorte pilot plant run. This instrument will be used to identify the chemical and isotopic composition of reaction products formed during CO hydrogenation reactions in the CMRU reactor.

In addition, a Hewlett-Packard gas chromatograph was installed during this reporting period. This instrument will be used to determine $\mathrm{CO}$ conversions by the use a Porapak R packed column and a thermal conductivity detector, using $\mathrm{Ar}$ as an unreactive internal standard to ensure accurate mass balances. A methyl-silicone capillary column is being used to separate all hydrocarbon and alcohol components; the concentration of these components in the column effluent will be obtained by flame ionization detection using standard Hewlett-Packard analysis software and response factors reported in the literature for these components.

The following activities were carried during this reporting period in the construction and start-up of CMRU:

- the single-pass flow reactor module has been designed, constructed, and pressure tested; the reactor dimensions were chosen to minimize heat transfer limitations and to avoid bypassing and channeling during integral reactor tests.

-the gas feed manifold, purification train, and transfer lines from the reactor to the gas chromatograph have been installed, heat traced where required, and pressure tested to $50 \mathrm{bar}(750 \mathrm{psig})$.

- the safety-interlocked CO monitor has been installed; the system logic is designed to isolate the $\mathrm{CO}$ cylinder from the unit when a $\mathrm{CO}$ release is detected or in the case of a power failure or hood shutdown. 
- all electrical components have been installed, tested, and calibrated and they are now operational

- the liquid introduction system (pump, liquid storage, and vaporizer parts) has been designed and constructed; final tests await the operation of the unit at steady-state with on-line sampling of concentrations in the process stream.

\section{Strategies for the Design of Isobutanol Synthesis Catalysts}

We have recently carried out an updated and more complete search of the scientific literature regarding the synthesis of methanol and higher alcohols with specific emphasis on the alcohol coupling pathways leading to isobutanol as a kinetic end-point. This literature study and extensive discussions within our research group has led to a gradual evolution in the details of the research strategy most likely to lead us to the desired target rates and selectivities.

Our initial strategy involves the separation of the isobutanol synthesis into three coupled steps: methanol synthesis, intermediate synthesis of ethanol $\left(C_{2}\right)$ by condensation reactions of methanol $\left(\mathrm{C}_{1}\right)$ or by chain growth carbonylation reactions, and an aldol condensation step of linear $\mathrm{C}_{1}-\mathrm{C}_{3}$ alcohol mixtures. Our research plan then addresses the site requirements and pathways for each independent step and their independent improvement before combining them together into one working catalyst.

$\mathrm{Cu} / \mathrm{ZnO}$ is a selective catalyst for the methanol synthesis step. Our initial catalytic studies will use the best available methanol synthesis catalysts (without further modification) as the hydrogenation/methanol synthesis component. The alcohol coupling steps involve dehydrogenation sites required to form aldehyde intermediates and a basic function to catalyze the subsequent chain growth by aldol condensation. A final hydrogenation step catalyzed by the dehydrogenation component then leads to the formation of branched alcohols as the final product.

Estimates of the rate of "diffusive" communication between two sites via gas phase reaction intermediates suggest that the hydrogenation-dehydrogenation and basic functions need to reside within 10-100 microns of each other in order to avoid significant depletion of required intermediates. Our initial experiments will test this proximity criterion by measuring the rate of alcohol coupling reactions on physical mixtures with varying levels of intimacy between the two functional components.

The rate controlling step in the synthesis of isobutanol from $\mathrm{CO}$ and $\mathrm{H}_{2}$ appears to be the chain growth of methanol to ethanol and higher alcohols. This reaction occurs predominately by alcohol coupling reactions during isobutanol synthesis on most catalytic materials reported in the literature. Two features of this reaction contribute to its low rate at isobutanol synthesis conditions. One of these is that base-catalyzed aldol 
condensation reaction require methanol dehydrogenation to formaldehyde before condensation. This dehydrogenation reaction can occur on $\mathrm{Cu}$-based hydrogenationdehydrogenation catalysts but the thermodynamics at isobutanol synthesis conditions are highly unfavorable because of the high $\mathrm{H}_{2}$ pressures. The second obstacle is introduced by the aldol condensation step itself, which must involve formaldehyde molecules lacking the $\beta$-hydrogens required for facile reaction. These mechanistic details are speculative at this time.

In the studies described below, we will isolate this critical step and conduct detailed studies of the rate and mechanism of this critical step on mixed-metal oxides with varying base strength and surface area. Concurrently, we will attempt to establish the extent to which this step is indeed the rate-controlling step in the synthesis of isobutanol at target reaction conditions.

\section{Mechanistic Studies of Alcohol Coupling Pathways}

A gradientless recirculating reactor will be used during the next quarter to examine turnover rates and elementary steps for reactions of methanol and ethanol on basic oxides with and without $\mathrm{Cu}$ promotion. These reactors permit the use of isotopic tracers in order to establish the molecular details of chain growth pathways during this reaction. These tracer studies will involve the use of ${ }^{13} \mathrm{C}$-labeled methanol and unlabeled ethanol to determine kinetic parameters for the intermediate steps involved.

Another possible pathway for overcoming the apparent bottleneck in alcohol chain growth during isobutanol synthesis is to dehydrate methanol to dimethylether and to isomerize the latter to ethanol. Aliphatic ethers undergo a Wittig rearrangement isomerization reaction catalyzed by strong homogeneous bases to form corresponding terminal alcohols [Advanced Organic Chemistry by J. March, Second edition, McGraw Hill, New York (1977) p 1015-1016; Wittig, Angew. Chem. 66, 10 (1954)]. This gradientless reactor will also be used to scope the catalytic properties of basic mixedmetal oxides in this isomerization reaction. The rate or mechanism of this reaction on solid bases have not been reported in the literature.

\section{Task 4: Identification of Reaction Intermediates}

Activities in this task have focused on a review of the existing literature on the use of temperature-programmed surface reaction methods. Project personnel have carried out a design and safety analysis of the Temperature-Programmed Surface Reaction/Infrared Unit (TPSR/IR) and proposed the design configuration described in Figure 2 of this report. All required parts have been specified and will be ordered during 3Q'95. The Leybold-Inficon Mass Spectrometer has been received and will be also be installed during 3Q'95. This instrument will be used for on-line analysis of the desorption products after dosing catalytic solids with various alcohols, hydrocarbons, $\mathrm{CO}$, or $\mathrm{H}_{2}$. 
The Mattson Infrared Spectrometer is now operational but lacks the flow capabilities required for in-situ studies. The gas inlet manifold and product analysis sections required to carry out these in-situ studies will be constructed as part of the TPSR apparatus. An in-situ infrared cell capable of operation at 10 bar and $300 \mathrm{C}$ has been designed, built, and tested. This infrared cell meets all design specifications and it is now operational. The detector configuration and cell location have been modified in order to improve chamber purging and to minimize background water and carbon dioxide. The new purge system also allows the choice of using a liquid nitrogen boil-off or cylinder nitrogen after water removal using molecular sieves.

\section{Task 5: Bench-Scale Catalyst Evaluation at Air Products and Chemicals}

APCI has provided a sample of a BASF isobutanol synthesis catalysts previously tested at the La Porte pilot plant. Representative data from this run have also been received and will be used to certify the performance of CMRU. This sample was provided to us under a no-analysis agreement and will be used exclusively in the initial certification run. 
Eig1: Schematic flow diagram of the Catalytic Microreactor unit

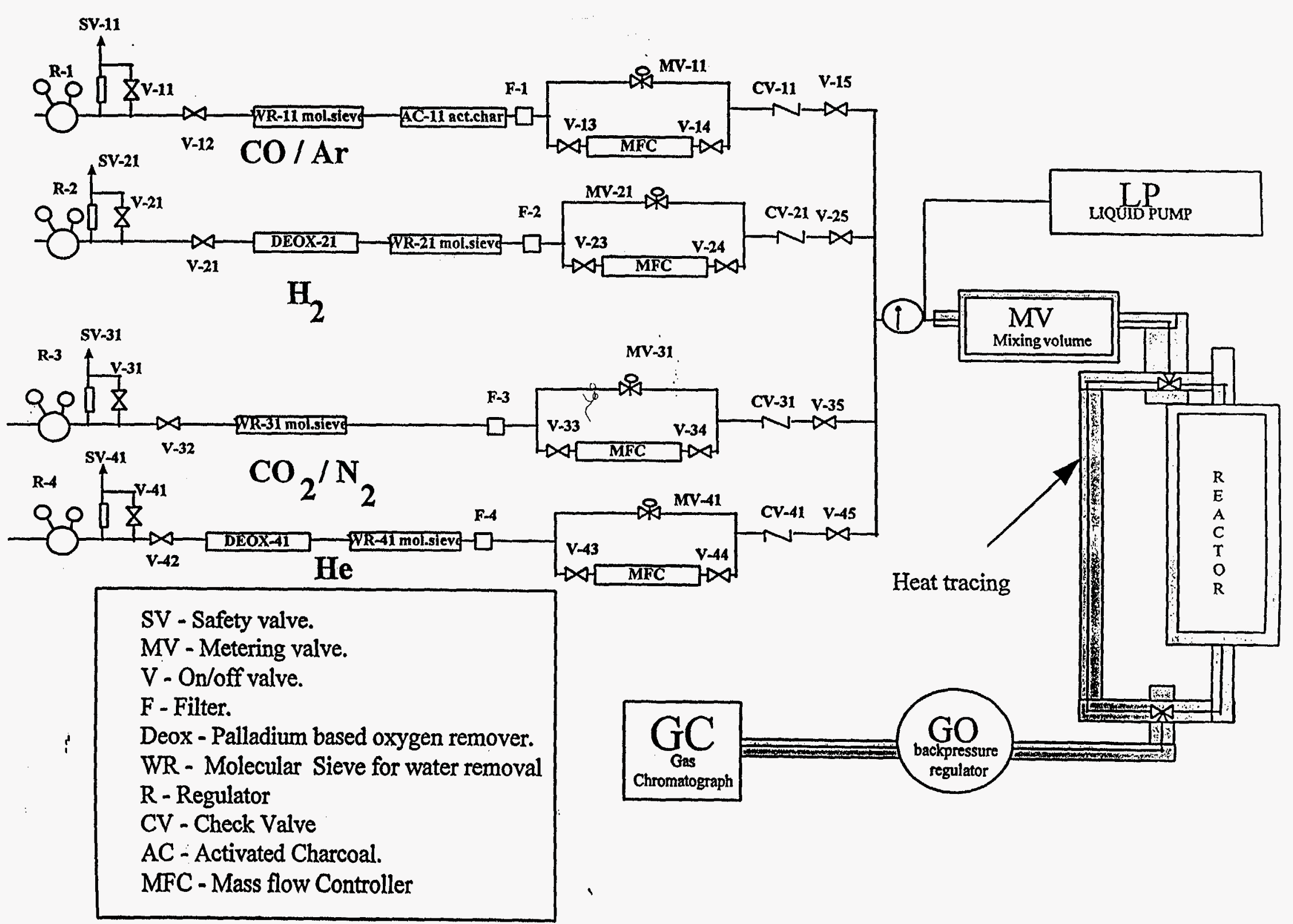


Eig 2: Schematic Flow diagram of the Temperature Programmed Surface Reaction / Infrared unit(TPSR /IR)

\section{Isotope}
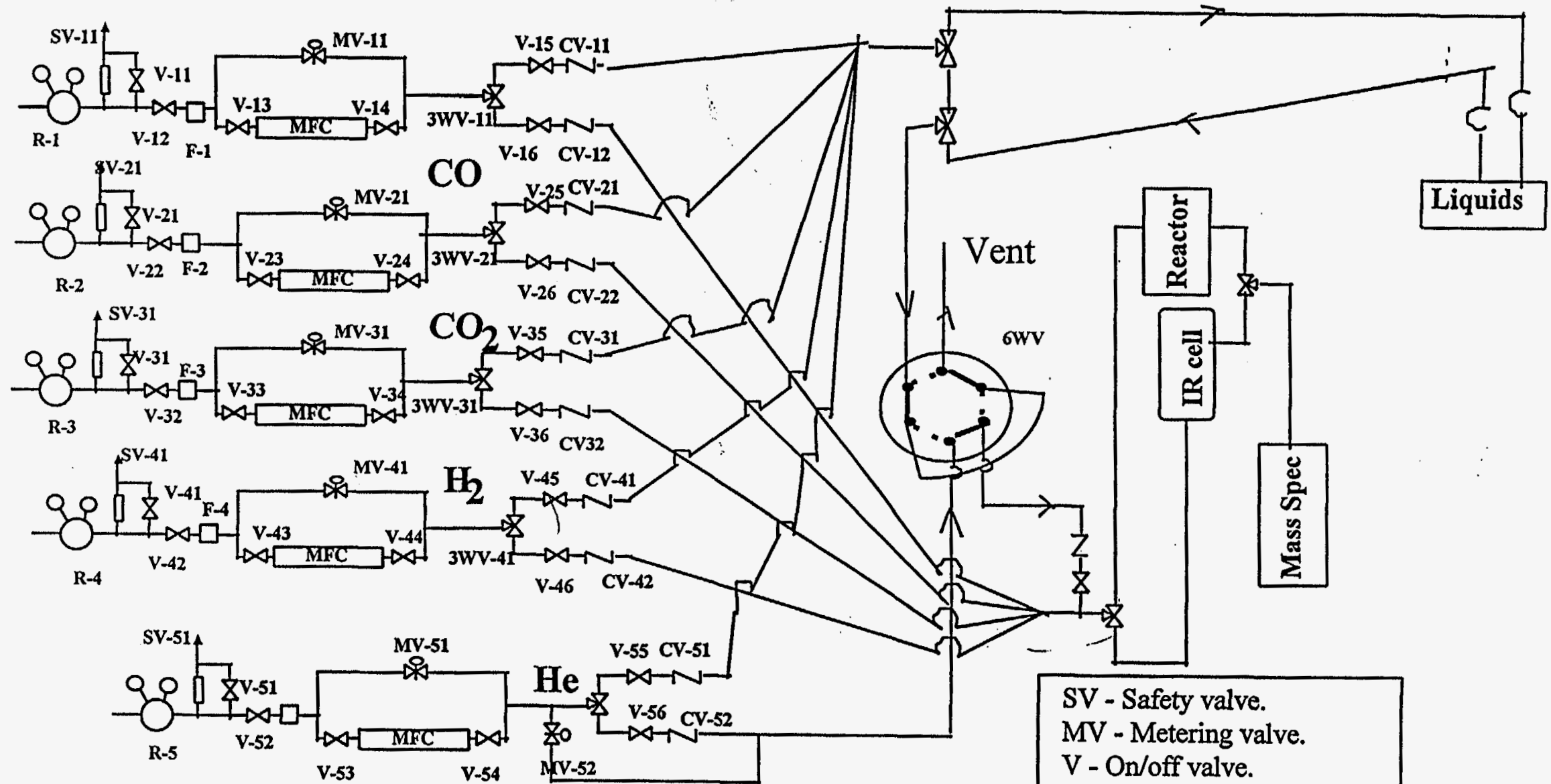

SV - Safety valve. MV - Metering valve. $\mathrm{V}$ - On/off valve.

F - Filter.

R - Regulator CV - Check Valve $3 \mathrm{WV}$ - 3-way valve 6WV - 6-way valve MFC - Mass flow Controller 